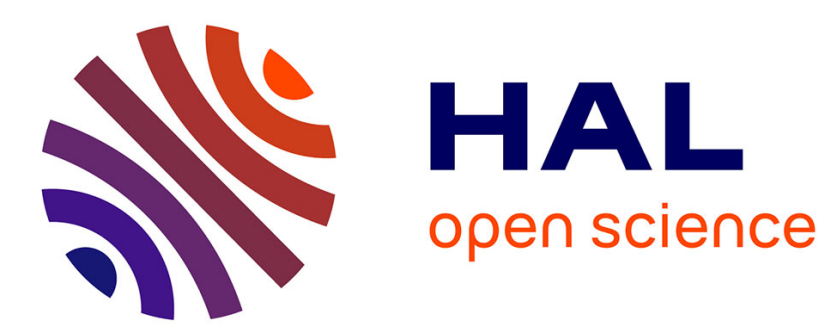

\title{
Analytic relations for partial alpha decay half-lives and barrier heights and positions
}

\author{
Guy Royer, C. Schreiber, H. Saulnier
}

\section{To cite this version:}

Guy Royer, C. Schreiber, H. Saulnier. Analytic relations for partial alpha decay half-lives and barrier heights and positions. International Workshop on State of the Art in Nuclear Cluster Physics (SOTANCP 2010), May 2010, Bruxelles, Belgium. pp.1030-1033, 10.1142/S0218301311019209. in2p3-00596855

HAL Id: in2p3-00596855

https://hal.in2p3.fr/in2p3-00596855

Submitted on 30 May 2011

HAL is a multi-disciplinary open access archive for the deposit and dissemination of scientific research documents, whether they are published or not. The documents may come from teaching and research institutions in France or abroad, or from public or private research centers.
L'archive ouverte pluridisciplinaire HAL, est destinée au dépôt et à la diffusion de documents scientifiques de niveau recherche, publiés ou non, émanant des établissements d'enseignement et de recherche français ou étrangers, des laboratoires publics ou privés. 


\title{
ANALYTIC RELATIONS FOR PARTIAL ALPHA DECAY HALF-LIVES AND BARRIER HEIGHTS AND POSITIONS
}

\author{
G. ROYER, C. SCHREIBER, H. SAULNIER \\ Subatech, UMR: IN2P3/CNRS-Université-Ecole des Mines, 44307 Nantes Cedex 03, France \\ royer@subatech.in2p3.fr \\ Received (received date) \\ Revised (revised date)
}

\begin{abstract}
From an adjustment on a recent selected data set of partial $\alpha$-decay half-lives of 344 ground state to ground state transitions, analytic formulae are proposed depending on the angular momentum of the $\alpha$ particle. In particular, an expression allows to reproduce precisely the partial $\alpha$-decay half-lives of even-even heavy nuclei and, then, to predict accurately the partial $\alpha$-decay half-lives of other very heavy elements from the experimental or predicted $Q_{\alpha}$. Simple expressions are also provided to calculate the potential barrier radius and height.
\end{abstract}

\section{Introduction}

In a previous study ${ }^{1}$ formulae have been proposed to calculate the total $\alpha$ decay half-lives of 373 emitters having an $\alpha$ branching ratio close to one. The rms deviation between the theoretical and experimental values of $\log _{10} T_{\alpha}(s)$ was respectively $0.285,0.39,0.36$ and 0.35 for the 131 even-even, $106 \operatorname{even}(\mathrm{Z})$-odd(N), 86 odd-even and 50 odd-odd nuclei. The predicted power of these formulae has been verified recently ${ }^{2}$ on new data and particularly for the heaviest elements.

In a recent paper $^{3}$, a carefully updated and selected partial $\alpha$ decay half-life data set of 344 ground-state-to-ground-state $\alpha$ transitions has been studied. The purpose of the present work is, firstly, to adjust the coefficients of the above-mentioned formulae $^{1}$ on this ground-state-to-ground-state decay data ${ }^{3}$ in incorporating a $l$ dependence and, secondly, to provide simple expressions to determine the alphadecay or capture barriers.

\section{Alpha-Decay Half-Lives of Isotopes of Charge $Z=117$}

Very recently ${ }^{4}$ the isotopes ${ }^{293} 117$ and ${ }^{294} 117$ were produced in fusion reactions between ${ }^{48} \mathrm{Ca}$ and ${ }^{249} \mathrm{Bk}$. Two decay chains were identified. 5 events correspond to the isotope ${ }^{293} 117$ and 1 event to the isotope ${ }^{294} 117$. In the Table 1 the characteristics of the two cascades are given : the range of the experimental $\mathrm{Q}$ value and the experimental $\alpha$-decay half-life and the values predicted using the above-mentioned 
Table 1. Comparison between the experimental and calculated $\alpha$-decay half-lives for the recent observed decay-chains originated from the isotopes $A=293$ and $A=294$ of the new element $\mathrm{Z}=117$.

\begin{tabular}{|c|c|c|c|c|c|c|c|}
\hline $\begin{array}{l}A \\
Z\end{array}$ & $\mathrm{Q}(\mathrm{MeV})$ & $T_{e x p}$ & $T_{\text {form }}$ & $\stackrel{A}{Z}$ & $\mathrm{Q}(\mathrm{MeV})$ & $T_{e x p}$ & $T_{\text {form }}$ \\
\hline $\begin{array}{l}293 \\
117\end{array}$ & $11.1-11.26$ & $10-25 \mathrm{~ms}$ & $9.7-24 \mathrm{~ms}$ & \multirow{5}{*}{$\begin{array}{l}289 \\
115 \\
294 \\
117 \\
286 \\
113 \\
278 \\
109\end{array}$} & $10.35-10.55$ & $0.14-0.48 \mathrm{~s}$ & $0.15-0.54 \mathrm{~s}$ \\
\hline $\begin{array}{l}285 \\
113\end{array}$ & $9.65-9.85$ & $3.7-10.5 \mathrm{~s}$ & $3.1-12.0 \mathrm{~s}$ & & $10.86-11.06$ & $0.042-0.45 \mathrm{~s}$ & $0.15-0.54 \mathrm{~s}$ \\
\hline $\begin{array}{l}290 \\
115\end{array}$ & $10.05-10.13$ & $0.016 \mathrm{~s}$ & $1.18-323 \mathrm{~s}$ & & $9.66-9.86$ & $19.6 \mathrm{~s}$ & $16.7-71.3 \mathrm{~s}$ \\
\hline $\begin{array}{l}110 \\
282 \\
111\end{array}$ & $9.03-9.23$ & $0.51 \mathrm{~s}$ & $314-1513 \mathrm{~s}$ & & $9.5-9.88$ & $7.6 \mathrm{~s}$ & $0.48-7.1 \mathrm{~s}$ \\
\hline $\begin{array}{l}274 \\
107\end{array}$ & $8.83-9.03$ & $54 \mathrm{~s}$ & $41-194 \mathrm{~s}$ & & & & \\
\hline
\end{tabular}

formulae ${ }^{1}$. There is a very good agreement for the cascade starting from the ${ }^{293} 117$ nucleus and for four nuclei of the other cascade. The disagreement is important for the ${ }^{290} 115$ and ${ }^{282} 111$ nuclei. In these two cases the experimental $\mathrm{Q}$ value is lower than expected.

\section{Analytic L-Dependent Formulae for the Partial Alpha Decay Half-Lives}

For the even-odd, odd-even and odd-odd nuclei the ground-state-to-ground-state transitions may occur for different spins and parities of the parent and daughter nuclei and, consequently, the $\alpha$ particle may take away an angular momentum $l$. According to the selection rules the minimal orbital angular momentum of the emitted $\alpha$ particle has been evaluated assuming that $l=0$ for all even-even nuclei ${ }^{3}$. From these $l$ values and for improving the accuracy of the preceding formulae an explicit dependence on $l$ has been researched and the following empirical formulae are proposed. They lead respectively for the 136 even-even, 84 even-odd, 76 oddeven and 48 odd-odd nuclei to a rms deviation of $0.328,0.5552,0.6661$ and 0.6807 .

$$
\begin{gathered}
\log _{10}[T]=-25.752-1.15055 A^{\frac{1}{6}} \sqrt{Z}+\frac{1.5913 Z}{\sqrt{Q}}, \\
\log _{10}[T]=-27.750-1.1138 A^{\frac{1}{6}} \sqrt{Z}+\frac{1.6378 Z}{\sqrt{Q}}+ \\
\frac{1.738310^{-6} A N Z[l(l+1)]^{\frac{1}{4}}}{Q}+0.002457 A\left[1-(-1)^{l}\right], \\
\log _{10}[T]=-27.915-1.1292 A^{\frac{1}{6}} \sqrt{Z}+\frac{1.6531 Z}{\sqrt{Q}}+ \\
\frac{8.978510^{-7} A N Z[l(l+1)]^{\frac{1}{4}}}{Q}+0.002513 A\left[1-(-1)^{l}\right], \\
\log _{10}[T]=-26.448-1.1023 A^{\frac{1}{6}} \sqrt{Z}+\frac{1.5967 Z}{\sqrt{Q}}+ \\
\frac{1.696110^{-6} A N Z[l(l+1)]^{\frac{1}{4}}}{Q}+0.00101 A\left[1-(-1)^{l}\right] .
\end{gathered}
$$


Additionally for the 59 heavy $(N>126$ and $Z>82)$ e-e nuclei of this data set the following formula

$$
\log _{10}[T]=-27.690-1.0441 A^{\frac{1}{6}} \sqrt{Z}+\frac{1.5702 Z}{\sqrt{Q}}
$$

leads to a very small rms deviation of 0.1867 while for the 77 remaining lighter e-e nuclei the expression

$$
\log _{10}[T]=-28.786-1.0329 A^{\frac{1}{6}} \sqrt{Z}+\frac{1.6127 Z}{\sqrt{Q}}
$$

leads to a rms deviation of only 0.2659 .

The $\mathrm{Q}_{\alpha}$ values ${ }^{5}$, the experimental ground state to ground state $\alpha$-decay halflives and values evaluated from the formula (1) are given in Table (2). For most of the nuclei, the difference between the experimental and theoretical data is relatively weak.

\section{Alpha Emission or Capture Barrier}

The alpha decay barrier is strongly lowered by the proximity energy with regard to the pure Coulomb barrier and the top of the barrier moves to a more external position corresponding to two separated spheres maintained in unstable equilibrium by the balance between the repulsive Coulomb forces and the attractive nuclear proximity forces. The main part of the barrier corresponds to two-body shapes.

The following expression allows to determine rapidly and accurately the distance between the mass centers at the $\alpha$ barrier top. A and $\mathrm{Z}$ are the mass and charge of the mother nucleus.

$$
R=2.536+1.1157\left[4^{\frac{1}{3}}+(A-4)^{\frac{1}{3}}\right] \quad f m .
$$

The height of the barrier against $\alpha$ decay can be determined using:

$$
E=-1.43+\frac{e^{2} \times 2 \times(Z-2)}{2.536+1.1157\left[4^{\frac{1}{3}}+(A-4)^{\frac{1}{3}}\right]}-Q \mathrm{MeV},
$$

from which the alpha-capture barrier height can be deduced in adding $\mathrm{Q}$.

\section{Conclusion}

Empirical expressions depending on the angular momentum of the $\alpha$ particle for the even-odd, odd-even and odd-odd nuclei are proposed to determine $\log _{10} T_{1 / 2}(s)$. The coefficients have been adjusted on a recent data set of partial $\alpha$-decay half-lives of 344 ground state to ground state transitions. An accurate expression is provided to evaluate the partial $\alpha$-decay half-lives of even-even heavy and superheavy elements from the experimental or predicted $Q_{\alpha}$. Analytic expressions are given to evaluate rapidly the $\alpha$-decay or capture barrier radius and height. 
Table 2. Comparison between the decimal logarithms of the experimental and calculated with the formula (1) ground state to ground state $\alpha$-decay half-lives (in s) for even-even nuclei.

\begin{tabular}{|c|c|c|c|c|c|c|c|}
\hline $\begin{array}{l}A \\
Z\end{array}$ & $\mathrm{Q}$ & $\log T_{e x p}$ & $\log T_{\text {form }}$ & $\begin{array}{l}A \\
Z\end{array}$ & $\mathrm{Q}$ & $\log T_{e x p}$ & $\log T_{\text {form }}$ \\
\hline 106 & 4.290 & -4.15 & -3.85 & 112 & 3.33 & 2.53 & 2.78 \\
\hline $\begin{array}{l}144 \\
60\end{array}$ & 1.905 & 22.86 & 23.02 & $\begin{array}{l}148 \\
62\end{array}$ & 1.986 & 23.34 & 23.42 \\
\hline $\begin{array}{l}150 \\
64\end{array}$ & 2.808 & 13.75 & 13.81 & $\begin{array}{l}150 \\
66\end{array}$ & 4.351 & 3.08 & 3.05 \\
\hline $\begin{array}{l}154 \\
66\end{array}$ & 2.946 & 13.98 & 13.80 & $\begin{array}{l}150 \\
68\end{array}$ & 4.28 & 4.68 & 4.59 \\
\hline $\begin{array}{l}00 \\
156 \\
70\end{array}$ & 4.811 & 2.42 & 2.699 & $\begin{array}{l}156 \\
72\end{array}$ & 6.028 & -1.63 & -1.74 \\
\hline $\begin{array}{l}160 \\
72\end{array}$ & 4.902 & 2.77 & 3.25 & $\begin{array}{l}174 \\
72\end{array}$ & 2.497 & 22.8 & 23.7 \\
\hline $\begin{array}{l}162 \\
74\end{array}$ & 5.677 & 0.46 & 0.56 & $\begin{array}{l}166 \\
74\end{array}$ & 4.856 & 4.74 & 4.48 \\
\hline $\begin{array}{l}162 \\
76\end{array}$ & 6.767 & -2.73 & -2.68 & $\begin{array}{l}164 \\
768\end{array}$ & 5.818 & 0.62 & 0.83 \\
\hline $\begin{array}{l}172 \\
76\end{array}$ & 5.227 & 3.98 & 3.49 & $\begin{array}{l}186 \\
76\end{array}$ & 2.823 & 22.8 & 22.3 \\
\hline $\begin{array}{l}170 \\
78\end{array}$ & 6.708 & -1.85 & -1.74 & $\begin{array}{l}176 \\
78\end{array}$ & 5.885 & 1.22 & 1.36 \\
\hline $\begin{array}{l}180 \\
78\end{array}$ & 5.24 & 4.24 & 4.33 & $\begin{array}{l}190 \\
78\end{array}$ & 3.251 & 19.31 & 18.72 \\
\hline $\begin{array}{l}176 \\
80\end{array}$ & 6.897 & -1.69 & -1.64 & $\begin{array}{l}182 \\
80\end{array}$ & 5.997 & 1.86 & 1.74 \\
\hline $\begin{array}{l}186 \\
80\end{array}$ & 5.205 & 5.71 & 5.46 & $\begin{array}{l}186 \\
82\end{array}$ & 6.47 & 0.68 & 0.66 \\
\hline $\begin{array}{l}190 \\
82\end{array}$ & 5.697 & 4.25 & 3.94 & $\begin{array}{l}194 \\
82\end{array}$ & 4.738 & 9.99 & 9.13 \\
\hline $\begin{array}{l}190 \\
84\end{array}$ & 7.693 & -2.59 & -2.84 & $\begin{array}{l}194 \\
84\end{array}$ & 6.987 & -0.38 & -0.55 \\
\hline $\begin{array}{l}198 \\
84\end{array}$ & 6.309 & 2.27 & 2.01 & $\begin{array}{l}202 \\
84\end{array}$ & 5.701 & 5.13 & 4.69 \\
\hline $\begin{array}{l}206 \\
84\end{array}$ & 5.327 & 7.14 & 6.54 & $\begin{array}{l}212 \\
84\end{array}$ & 8.954 & -6.52 & -6.83 \\
\hline $\begin{array}{l}216 \\
84\end{array}$ & 6.906 & -0.84 & -0.72 & $\begin{array}{l}198 \\
86\end{array}$ & 7.349 & -1.18 & -1.03 \\
\hline $\begin{array}{l}204 \\
86\end{array}$ & 6.384 & 2.74 & 2.48 & $\begin{array}{l}20 \\
210 \\
86\end{array}$ & 6.159 & 3.95 & 3.38 \\
\hline $\begin{array}{l}214 \\
86\end{array}$ & 9.208 & -6.57 & -6.75 & $\begin{array}{l}218 \\
86\end{array}$ & 7.263 & -1.46 & -1.15 \\
\hline $\begin{array}{l}222 \\
86\end{array}$ & 5.59 & 5.52 & 5.88 & $\begin{array}{l}210 \\
88\end{array}$ & 7.152 & 0.57 & 0.30 \\
\hline $\begin{array}{l}214 \\
88\end{array}$ & 7.273 & 0.39 & -0.22 & $\begin{array}{l}218 \\
88\end{array}$ & 8.546 & -4.59 & -4.33 \\
\hline $\begin{array}{l}222 \\
88\end{array}$ & 6.679 & 1.59 & 1.88 & $\begin{array}{l}226 \\
88\end{array}$ & 4.871 & 10.73 & 11.06 \\
\hline $\begin{array}{l}218 \\
90\end{array}$ & 9.849 & -6.96 & -6.89 & $\begin{array}{l}222 \\
90\end{array}$ & 8.127 & -2.69 & -2.37 \\
\hline $\begin{array}{l}226 \\
90\end{array}$ & 6.45 & 3.39 & 3.70 & $\begin{array}{l}230 \\
90\end{array}$ & 4.77 & 12.49 & 12.81 \\
\hline $\begin{array}{l}226 \\
92\end{array}$ & 7.701 & -0.57 & -0.23 & $\begin{array}{l}230 \\
92\end{array}$ & 5.993 & 6.43 & 6.74 \\
\hline $\begin{array}{l}234 \\
92\end{array}$ & 4.858 & 13.04 & 13.28 & $\begin{array}{l}238 \\
92\end{array}$ & 4.27 & 17.25 & 17.62 \\
\hline $\begin{array}{l}234 \\
94\end{array}$ & 6.31 & 5.89 & 6.11 & $\begin{array}{l}238 \\
94\end{array}$ & 5.593 & 9.59 & 9.73 \\
\hline $\begin{array}{l}242 \\
94\end{array}$ & 4.985 & 13.18 & 13.40 & $\begin{array}{l}238 \\
96\end{array}$ & 6.62 & 5.51 & 5.56 \\
\hline $\begin{array}{l}242 \\
96\end{array}$ & 6.216 & 7.28 & 7.38 & $\begin{array}{l}20 \\
246\end{array}$ & 5.475 & 11.26 & 11.32 \\
\hline $\begin{array}{l}240 \\
98\end{array}$ & 7.719 & 2.03 & 1.99 & $\begin{array}{l}248 \\
98\end{array}$ & 6.361 & 7.56 & 7.53 \\
\hline $\begin{array}{l}252 \\
98\end{array}$ & 6.217 & 8.01 & 8.17 & $\begin{array}{l}246 \\
100\end{array}$ & 8.378 & 0.17 & 0.43 \\
\hline $\begin{array}{l}250 \\
100\end{array}$ & 7.557 & 3.38 & 3.26 & $\begin{array}{l}254 \\
100\end{array}$ & 7.308 & 4.14 & 4.16 \\
\hline $\begin{array}{l}252 \\
102\end{array}$ & 8.55 & 0.74 & 0.55 & $\begin{array}{l}256 \\
102\end{array}$ & 8.581 & 0.53 & 0.38 \\
\hline
\end{tabular}

\section{References}

1. G. Royer, J. Phys. G: Nucl. Part. Phys. 26 (2000) 1149.

2. G. Royer and H. F. Zhang, Phys. Rev. C 77 (2008) 037602.

3. V. Yu. Denisov and A. A. Khudenko, At. Data Nucl. Data Tables 95 (2009) 815.

4. Yu. Ts. Oganessian et al., Phys. Rev. Lett. 104 (2010) 142502.

5. G. Audi, A. H. Wapstra and C. Thibault, Nucl. Phys. A 729 (2003) 337. 